TERRES LR; LENZ E; CASTRO CM; PEREIRA AS. 2015. Estimativas de ganhos genéticos por diferentes índices de seleção em três populações híbridas de batata. Horticultura Brasileira 33: 305-310. DOI: http://dx.doi.org/10.1590/S0102-053620150000300005

\title{
Estimativas de ganhos genéticos por diferentes índices de seleção em três populações híbridas de batata
}

\author{
Laerte R Terres ${ }^{1}$; Emerson Lenz ${ }^{1}$; Caroline M Castro² ${ }^{2}$ Arione S Pereira ${ }^{2}$ \\ 'Universidade Federal de Pelotas; Pelotas-RS, Brasil; laerte_terres@yahoo.com.br (autor para correspondência); ${ }^{2}$ Embrapa Clima \\ Temperado, Pelotas-RS, Brasil; caroline.castro@embrapa.br, arione.pereira@embrapa.br
}

\begin{abstract}
RESUMO
O objetivo deste trabalho foi comparar a eficiência de diferentes índices de seleção de clones superiores de batata. $\mathrm{O}$ experimento foi realizado no campo experimental da Embrapa Clima Temperado em Pelotas-RS, na primavera de 2008. Foram estudadas três populações híbridas de batata derivadas de cruzamentos entre clones avançados do programa de melhoramento de batata da Embrapa e cultivares estrangeiras. O delineamento experimental foi blocos aumentados em quatro repetições. $\mathrm{O}$ uso de índices de seleção resultou em maiores estimativas de ganhos de seleção, com melhor distribuição entre os caracteres avaliados. Os melhores índices de seleção encontrados para serem utilizados em programas de melhoramento de batata são os índices multiplicativo de Subandi et al. (1973) e o índice baseado na soma de ranks proposto por Mulamba \& Mock (1978).
\end{abstract}

Palavras-chave: Solanum tuberosum, melhoramento genético, herdabilidade.

\begin{abstract}
Genetic gain estimates using different selection index methods in three potato hybrid populations

The objective of this study was to compare the efficiency of different selection index methods for superior potato clones. The experiment was carried out at the experimental field of Embrapa Clima Temperado in Pelotas, Rio Grande do Sul State, Brazil, in the spring season of 2008. Three hybrid populations of potato derived from crosses between advanced clones of Embrapa potato breeding program and foreign cultivars were studied. The experimental design was an augmented block with four replications. The use of selection indexes resulted in higher selection gains, with better distribution among traits. The best selection index found to be used in potato breeding programs are the multiplicative of Subandi et al. (1973) and the index based on the sum of ranks proposed by Mulamba \& Mock (1978).
\end{abstract}

Keywords: Solanum tuberosum, breeding, heritability.

(Recebido para publicação em 26 de março de 2014; aceito em 26 de fevereiro de 2015) (Received on March 26, 2014; accepted on February 26, 2015)

\begin{abstract}
A batata (Solanum tuberosum) é o terceiro cultivo alimentar mais importante no mundo, superada em consumo apenas por arroz e trigo (FAO, 2012). No Brasil, a cultura está entre os dez principais produtos agrícolas e é a hortaliça de maior importância econômica (Pineli et al., 2005). Os programas de melhoramento genético da cultura são essenciais para atender a crescente demanda por novas cultivares, possibilitando, com a ampliação da base genética, a seleção dos melhores genótipos capazes de superar os patamares atuais. Contudo, em batata, selecionar genótipos superiores não é uma tarefa fácil, uma vez que uma cultivar precisa combinar mais de 50 características (Ross, 1986). A seleção torna-se ainda um desafio maior para os melhoristas
\end{abstract}

por as diferenças entre essas características serem cada vez menores e o número de caracteres maiores (Silva et al., 2007).

Durante as várias gerações de seleção, atenção deve ser dada a caracteres que atendam da melhor forma possível aos consumidores (qualidade visual e culinária), aos produtores (maior rendimento) e às indústrias (qualidade de fritura). Dentre os caracteres de maior importância, se destacam a aparência do tubérculo, os caracteres componentes de rendimento e aqueles relacionados à qualidade industrial (Pereira, 2003).

A aparência do tubérculo é um caráter complexo e dependente de vários caracteres mais simples, apresentando assim baixa herdabilidade (Tai \& Young,
1984; Silva et al., 2008). No entanto, seus componentes, como a textura e a cor da película, apresentam herdabilidade de maior magnitude, que possibilitam maior eficiência de seleção (Love et al., 1997; Silva et al., 2007).

A seleção baseada em um ou em poucos caracteres pode se mostrar inadequada, uma vez que conduz a um produto final superior apenas em relação aos caracteres selecionados (Cruz \& Carneiro, 2006). Uma alternativa seria a seleção simultânea de um conjunto de caracteres de expressividade econômica, visando aumentar o êxito do programa de melhoramento. Desta forma, o melhoramento pode ser ainda mais efetivo com a utilização de índices de seleção, estabelecido pela combinação linear ótima de vários caracteres, para uma 
seleção simultânea (Cruz \& Carneiro, 2006).

$\mathrm{Na}$ literatura são encontrados vários índices de seleção propostos para ser utilizados no melhoramento de plantas (Cruz, 2006). Apesar da aplicabilidade dos índices de seleção ter sido reportada para diversas culturas (Granate et al., 2002; Martins et al., 2003; Costa et al., 2004; Pedrozo et al., 2009; Silva et al., 2009; Vasconcelos et al., 2010), em batata poucos são os estudos empregando índices de seleção (Tai, 1977; Barbosa \& Pinto 1998; Lambert et al., 2006), visto que nesta espécie são mais comumente utilizados os níveis independentes de eliminação como critério de seleção. Entretanto, o uso de índices de seleção pode melhorar o processo de seleção em batata, por ser mais eficiente que o método dos níveis independentes (Barbosa \& Pinto, 1998).

O objetivo deste trabalho foi comparar a eficiência de diferentes índices de seleção por meio de seus ganhos estimados, na seleção de clones superiores de batata.

\section{MATERIAL E MÉTODOS}

$\mathrm{O}$ experimento foi realizado no campo experimental da Embrapa Clima Temperado em Pelotas-RS (31 ${ }^{\circ} 40^{\prime} 18^{\prime}$ 'S, $52^{\circ} 26^{\prime} 15^{\prime}$ 'O, $60 \mathrm{~m}$ acima do nível do mar), durante a safra de primavera de 2008. O solo é classificado como Argissolo Vermelho-Amarelo Distrófico Típico, sendo fertilizado nas áreas de plantio com 2 t/ha de NPK (5-30-10). Os tratos culturais e fitossanitários foram similares aos realizados em plantios comerciais da região.

Foram estudadas três populações híbridas de batata derivadas de cruzamentos entre clones avançados do programa de melhoramento de batata da Embrapa e cultivares estrangeiras: População C-1168 ( $\mathrm{n}=71)$, obtida do cruzamento Atlantic/C1226-35-80; população C-1172 $(\mathrm{n}=55)$, derivada do cruzamento C1226-35-80/Vivaldi; e população C-1179 ( $\mathrm{n}=70)$, obtida do cruzamento Atlantic/Eliza. A cultivar Atlantic apresenta tubérculos com formato arredondado, película amarela e áspera, polpa branca e gemas meio profundas; o clone C1226-35-80 apresenta tubérculos com formato ovalado e achatado, película amarela e levemente áspera, polpa amarela e gemas rasas; e a cultivar Vivaldi apresenta tubérculos com formato ovalado, película amarela e lisa, polpa amarela e gemas rasas. Além das três populações, foram avaliadas as cultivares Agata, Monalisa, Eliza, Atlantic e Delta-S, e os clones avançados C1786-7-96, C1750-15-95 e C1742-8-95, como testemunhas, representando a amplitude de variação quanto aos caracteres avaliados. O delineamento experimental foi blocos aumentados (Federer, 1955). As testemunhas foram repetidas quatro vezes, num delineamento em blocos casualizados, e os clones das populações não foram repetidos: foram distribuídos ao acaso, nos blocos do experimento. Cada bloco foi constituído por 49 parcelas, e cada uma composta por três tubérculos, espaçados em $80 \mathrm{~cm}$ entre fileiras e 30 $\mathrm{cm}$ dentro da fileira.

Após a colheita, os tubérculos foram classificados quanto ao tamanho (tubérculos comerciais: $>45 \mathrm{~mm}$ de diâmetro transversal; não comerciais: $\leq 45 \mathrm{~mm}$ ) e avaliados em relação a caracteres componentes de rendimento: massa total de tubérculos (MTT), percentual de tubérculos comerciais (PER) e massa média de tubérculos (MME), que foi obtida por meio da razão entre a massa total e o número de tubérculos. Posteriormente foi avaliada a textura da película dos tubérculos (TEX), utilizando escala de notas de cinco pontos $(1=$ textura áspera; $5=$ textura lisa). Para facilitar a visualização da textura, os tubérculos foram lavados imediatamente antes da avaliação.

As análises estatísticas foram efetuadas com o auxílio do programa Genes (Cruz, 2006). Os dados foram submetidos à análise de homogeneidade de variância (teste de Bartllet) e de normalidade (Lilliefors). Os dados de textura foram transformados para $\sqrt{x} \mathrm{e}$ de percentual de tubérculos comerciais para $\sqrt{x+0,5}$, visando atender à pressuposição de normalidade de distribuição do erro. Foram estimados os coeficientes de herdabilidade no sentido amplo pelo quadrado médio (Cruz \& Carneiro, 2006).
Os índices empregados para seleção dos melhores genótipos foram: seleção direta e indireta, índice clássico (Smith, 1936; Hazel, 1943), índice baseado em soma de ranks (Mulamba \& Mock, 1978), índice base (Willians, 1962), índice baseado nos ganhos desejados (Pesek \& Baker, 1969), índice livre de pesos e parâmetros de Elston (1963) e índice multiplicativo (Subandi et al., 1973).

O ganho esperado pela seleção direta no i-ésimo caráter pode ser estimado por:

$\mathrm{GS}_{\mathrm{i}}=\left(\overline{\mathrm{X}}_{\mathrm{si}}-\overline{\mathrm{X}}_{\mathrm{oi}}\right) \mathrm{h}_{\mathrm{i}}^{2}=\mathrm{DS}_{\mathrm{i}} \mathrm{h}_{\mathrm{i}}^{2}$ em que $\overline{\mathrm{X}}_{\mathrm{si}}$ é a média dos indivíduos selecionados para o caráter $\mathrm{i} ; \overline{\mathrm{x}}_{\mathrm{oi}}$ é média original da população; DS é o diferencial de seleção praticado na população; e $h^{2}{ }_{i}$ é a herdabilidade para o caráter i.

$\mathrm{O}$ ganho indireto no caráter $\mathrm{j}$, pela seleção no caráter $\mathrm{i}$, é dado por:

$$
\mathrm{GS}_{\mathrm{j}(\mathrm{i})}=\mathrm{DS}_{\mathrm{j}(\mathrm{i})} \mathrm{h}_{\mathrm{j}}^{2}
$$

em que $\mathrm{DS}_{\mathrm{j}(\mathrm{i})}$ é o diferencial de seleção indireta obtida em função da média do caráter daqueles indivíduos cuja superioridade foi evidenciada com base em outro caráter, sobre o qual se pratica a seleção direta.

O índice clássico, proposto por Smith (1936) e Hazel (1943), consiste em uma combinação linear dos vários caracteres, no qual os coeficientes de ponderação são estimados de modo a maximizar a sua correlação com o agregado genotípico que é estabelecido por uma outra combinação linear envolvendo os valores genéticos dos caracteres, ponderados pelos seus respectivos pesos econômicos. Considerando que $\mathrm{H}=\mathrm{a}_{1} \mathrm{~g}_{1}+\mathrm{a}_{2} \mathrm{~g}_{2}+\cdots+\mathrm{a}_{\mathrm{n}} \mathrm{g}_{\mathrm{n}}=\sum_{\mathrm{i}=1}^{\mathrm{n}} \mathrm{a}_{\mathrm{i}} \mathrm{g}_{\mathrm{i}}=\mathrm{g}^{\prime} \mathrm{a}$ e $\mathrm{I}=\mathrm{b}_{1} \mathrm{y}_{1}+\mathrm{b}_{2} \mathrm{y}_{2}+\cdots+\mathrm{b}_{\mathrm{n}} \mathrm{y}_{\mathrm{n}}=\sum_{\mathrm{i}=1}^{\mathrm{n}} \mathrm{b}_{\mathrm{i}} \mathrm{y}_{\mathrm{i}}=\mathrm{y}^{\prime} \mathrm{b}$ em que $\mathrm{H}$ é o agregado genotípico; I é o índice de seleção; n é o número de caracteres avaliados; g' é o vetor de dimensão 1 x n de valores genéticos desconhecidos dos $n$ caracteres considerados; y' é o vetor de dimensão 1 x n de valores fenotípicos dos caracteres; a é o vetor de dimensão $\mathrm{n} \times 1$ de valores econômicos previamente estabelecidos; e b o vetor de dimensão $\mathrm{n} \times 1$ dos coeficientes de ponderação do índice de seleção a ser estimado.

$\mathrm{P}$ é a matriz de dimensão $\mathrm{n} \times \mathrm{n}$ de 
variâncias e covariâncias fenotípicas, e $\mathrm{G}$ a matriz de dimensão $\mathrm{n} x \mathrm{n}$ de covariâncias genéticas entre os caracteres. $\mathrm{O}$ vetor $\mathrm{b}$ é estimado por meio de $\mathrm{b}=\mathrm{P}^{-1} \mathrm{G}$.

$\mathrm{O}$ ganho esperado no caráter $\mathrm{j}$, quando a seleção é praticada sobre o índice, é expresso por:

$$
\Delta \mathrm{g}_{\mathrm{j}(\mathrm{I})}=\mathrm{DS}_{\mathrm{j}(\mathrm{I})} \mathrm{h}_{\mathrm{j}}^{\mathrm{z}}
$$

em que $\mathrm{g}_{\mathrm{j}(\mathrm{I})}$ é o ganho esperado para o caráter $\mathrm{j}$, com a seleção baseada no índice $\mathrm{I} ; \mathrm{j}_{\text {(I) }}$ é o diferencial de seleção do caráter j, com a seleção baseada no índice I; e $\mathrm{h}^{2}{ }_{\mathrm{j}}$ é a herdabilidade no caráter $\mathrm{j}$.

O índice baseado na soma de ranks (Mulamba \& Mock, 1978) hierarquiza os genótipos, inicialmente, para cada característica, por meio da atribuição de valores absolutos mais elevados àqueles de melhor desempenho. Por fim, são somadas as ordens de cada material, referente a cada caráter, resultando no índice de seleção, como descrito a seguir: $\mathrm{I}=\mathrm{r}_{1}+\mathrm{r}_{2}+\ldots+\mathrm{r}_{\mathrm{n}}$, sendo I o valor do índice para determinado indíviduo,

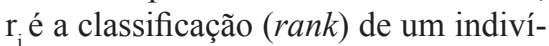
duo em relação à j-ésima variável e $n$ o número de variáveis consideradas no índice. Adicionalmente, o procedimento permite que a ordem de classificação das variáveis tenha pesos diferentes, conforme especificado pelo melhorista. Assim, tem-se que $\mathrm{I}=\mathrm{p}_{1} \mathrm{r}_{1}+\mathrm{p}_{2} \mathrm{r}_{2}+\ldots+\mathrm{p}_{\mathrm{n}} \mathrm{r}_{\mathrm{n}}$, sendo $\mathrm{p}_{\mathrm{j}}$ o peso econômico atribuído pelo usuário à j-ésima característica.

O índice base (Willians, 1962) consiste em estimar um índice dado pela combinação linear dos valores fenotípicos médios dos caracteres, os quais são ponderados diretamente pelos respectivos pesos econômicos. $\mathrm{O}$ índice é estimado por: $\mathrm{I}=\mathrm{a}_{1} \mathrm{y}_{1}+\mathrm{a}_{2} \mathrm{y}_{2}+\ldots+\mathrm{a}_{\mathrm{n}}$ $\mathrm{y}_{\mathrm{n}}=\mathrm{y}^{\prime} \mathrm{a}$, sendo $\mathrm{y}_{\mathrm{j}}$ média da j-ésima característica e $\mathrm{p}_{\mathrm{j}}$ o peso econômico.

$\mathrm{O}$ índice baseado nos ganhos desejados (Pesek \& Baker, 1969) propõe substituir os pesos econômicos pelos ganhos desejados pelo melhorista para cada caráter. Sendo todos caracteres considerados como principais, os coeficientes de ponderação do índice são: $\mathrm{b}=\mathrm{G}^{-1} \Delta \mathrm{g}_{\mathrm{d}}$, em que $\Delta g_{d}$ é o vetor de ganhos desejados estabelecido pelo melhorista.

No índice livre de pesos e parâmetros (Elston, 1963), o melhorista estabelece os respectivos critérios de seleção e os limites máximos (ou mí- nimos) abaixo (ou acima) dos quais os genótipos são selecionados. O índice é estimado por: $\mathrm{I}=\omega_{1} \omega_{2} \ldots \omega_{\mathrm{n}}$, em que $\omega_{\mathrm{j}}=\mathrm{y}_{\mathrm{j}}-\mathrm{k}_{\mathrm{j}}$, sendo $\mathrm{k}_{\mathrm{j}} \mathrm{um}$ valor mínimo (ou máximo) estabelecido pelo melhorista para o i-ésimo caráter.

No índice multiplicativo (Subandi et al., 1973), é pressuposto que o índice seja diretamente proporcional à variável analisada, ou inversamente de acordo com o desejado pelo melhorista. O índice é estimado por:

$$
\mathrm{I}=\mathrm{y}_{1}^{\mathrm{k} 1} \mathrm{y}_{2}^{\mathrm{k} 2} \ldots \mathrm{y}_{\mathrm{n}}^{\mathrm{kn}}:
$$

em que: $y_{\mathrm{j}}$ é o valor do caráter no caráter $\mathrm{j}, \mathrm{k}_{\mathrm{j}}=1$, se for considerada a relação direta do índice com a variável e $\mathrm{k}_{\mathrm{j}}=-1$, se for considerada a relação inversa do índice com a variável.

Para análise de ganho genético, os pesos econômicos dos caracteres principais e ganhos desejados foram estabelecidos a partir dos próprios dados experimentais, conforme recomendações de Cruz (2006). Primeiro, realizou-se uma comparação entre os ganhos obtidos pela seleção direta e indireta em cada caráter e pelo índice clássico de Smith e Hazel, em que apenas um caráter era considerado como principal e com peso econômico de valor um (1), e os caracteres secundários com peso zero. Posteriormente, compararam-se os índices em três situações diferentes:
$\mathrm{I}=$ massa total de tubérculo, massa média dos tubérculos e percentual de tubérculos comerciais, como principais; $\mathrm{II}=$ textura, como principal; $\mathrm{III}=$ todos caracteres como principais.

Como os pesos econômicos estabelecidos para os caracteres principais, adotou-se valor um (1), às estimativas de coeficiente de variação genético $(\mathrm{CVg})$ e o equivalente a um desvio-padrão genético (DP), com os valores secundários assumindo valores nulos. Para o índice de Elston (1963), os valores mínimos foram iguais à média para cada caráter. Todos os procedimentos estatísticos necessários para a construção dos índices de seleção foram realizados com o auxílio do programa Genes (Cruz, 2006).

\section{RESULTADOS E DISCUSSÃO}

A análise de variância revelou diferenças significativas para todos os caracteres, isto é, massa total de tubérculos, percentual de tubérculos comerciais, massa média dos tubérculos e textura da película. Os coeficientes de variação (CV) oscilaram de 21,23 a 36,30\% para os caracteres massa total de tubérculo e percentual de tubérculos comerciais, respectivamente. Estes CVs foram semelhantes aos valores encontrados

Tabela 1. Estimativas das médias, herdabilidades $\left(\mathrm{h}^{2}\right)$ e ganhos de seleção em porcentagem (GS\%), obtidos pela seleção direta e indireta (SEL) e pelo índice clássico de Smith (1936) e Hazel (1943) (SH), em três populações híbridas de batata, considerando cada caráter como principal (mean, heritability $\left(\mathrm{h}^{2}\right)$ and selection gain estimates in percentage (GS\%), obtained by direct and indirect selection (SEL), and by the classic index of Smith (1936) and Hazel (1943) (SH), in three hybrid potato populations, considering each trait as principal $\}$. Pelotas,

\begin{tabular}{|c|c|c|c|c|c|c|c|c|}
\hline \multirow{2}{*}{ Variável } & \multirow{2}{*}{ Média } & \multirow{2}{*}{$1^{2}$} & \multirow{2}{*}{ Seleção } & \multicolumn{5}{|c|}{ GS (\%) } \\
\hline & & & & MTT & PER & MME & TEX & Total \\
\hline \multirow[t]{2}{*}{ MTT } & 1335,28 & 72,51 & SEL & 69,78 & 24,11 & 22,06 & $-2,80$ & 113,15 \\
\hline & & & SH & 68,01 & 28,26 & 20,58 & 2,72 & 119,57 \\
\hline \multirow[t]{2}{*}{ PER } & 35,30 & 63,13 & SEL & 9,96 & 79,22 & 47,56 & $-20,00$ & 116,74 \\
\hline & & & S & 21,84 & 76,19 & 49,68 & $-18,42$ & 129,29 \\
\hline \multirow[t]{2}{*}{ MME } & 51,22 & 57,80 & SEL & 15,85 & 68,19 & 53,73 & $-12,42$ & 125,35 \\
\hline & & & $\mathrm{SH}$ & 26,78 & 74,95 & 47,52 & $-11,79$ & 137,46 \\
\hline \multirow[t]{2}{*}{ TEX } & 2,46 & 61,69 & SEL & $-6,26$ & $-3,27$ & $-4,15$ & 52,27 & 38,59 \\
\hline & & & SH & 8,51 & 7,58 & 14,31 & 44,53 & 74,93 \\
\hline
\end{tabular}
UFPel, 2014.

MTT= Massa total de tubérculos (total tuber yield); $\mathrm{PER}=$ percentual de tubérculos comerciais (percentage of marketable tubers); $\mathrm{MME}=$ massa média de tubérculos (average tuber weight); TEX= textura de película dos tubérculos (skin texture of tubers). 
Tabela 2. Estimativas de ganhos com a seleção (GS\%) para caracteres de rendimento e aparência de tubérculos de batata pelos índices propostos por Smith (1936) e Hazel (1943), (SH), Mulamba \& Mock (1978) (MM), Willians (1962) (BW), Pesek \& Baker (1969) (PB), multiplicativo de Subandi et al. (1973) (MUL) e Elston (1963) (ELS), com os pesos econômicos e ganhos desejados (PE/GD), e respectivas situações de seleção \{estimated selection gains (GS\%) for the yield and tuber appearance traits of potatoes by the indexes proposed by Smith (1936) and Hazel (1943) (SH), Mulamba \& Mock (1978) (MM), Williams (1962) (BW), Pesek \& Baker (1969) (PB), multiplicative of Subandi et al. (1973) (MUL), and Elston (1963) (ELS), with economic weight and desired gains (PE/GD), and respective selection situations) $\}$. Pelotas, UFPel, 2014.

\begin{tabular}{|c|c|c|c|c|c|c|c|}
\hline \multirow{2}{*}{ Índice } & \multirow{2}{*}{ PE/GD } & \multirow{2}{*}{ Situação } & \multicolumn{5}{|c|}{ GS (\%) } \\
\hline & & & PER & MME & MTT & TEX & Total \\
\hline \multirow[t]{3}{*}{$\mathrm{SH}$} & 1 & $\mathrm{I}^{1}$ & 24,11 & 22,06 & 69,78 & $-1,15$ & 114,80 \\
\hline & & $\mathrm{II}^{2}$ & $-4,03$ & 7,12 & 2,42 & 76,96 & 82,47 \\
\hline & & $\mathrm{III}^{3}$ & 28,26 & 20,58 & 68,01 & 7,39 & 124,24 \\
\hline \multirow[t]{3}{*}{ SH } & $\mathrm{CVg}^{4}$ & I & 27,24 & 19,82 & 67,66 & 9,27 & 121,99 \\
\hline & & II & $-2,71$ & $-2,30$ & $-2,52$ & 82,36 & 74,83 \\
\hline & & III & 31,18 & 24,16 & 68,50 & $-3,31$ & 120,53 \\
\hline \multirow[t]{3}{*}{ SH } & $\mathrm{DP}^{5}$ & I & 20,03 & 19,82 & 67,66 & 2,99 & 110,50 \\
\hline & & II & 0,48 & $-1,68$ & $-1,95$ & 77,82 & 74,67 \\
\hline & & III & 20,03 & 19,82 & 67,66 & 2,99 & 110,50 \\
\hline \multirow[t]{3}{*}{ MM } & 1 & I & 58,78 & 40,32 & 49,91 & $-14,82$ & 134,19 \\
\hline & & II & 5,12 & 0,37 & $-5,65$ & 80,76 & 80,60 \\
\hline & & III & 39,56 & 29,83 & 33,60 & 62,27 & 165,20 \\
\hline \multirow[t]{3}{*}{ MM } & $\mathrm{CVg}$ & I & 64,20 & 41,36 & 43,66 & $-14,09$ & 135,13 \\
\hline & & II & 6,66 & 2,35 & $-1,65$ & 80,76 & 88,12 \\
\hline & & III & 43,92 & 33,02 & 35,89 & 54,43 & 167,26 \\
\hline \multirow[t]{3}{*}{ MM } & $\mathrm{DP}$ & I & 21,07 & 26,89 & 68,51 & $-3,99$ & 112,48 \\
\hline & & II & 0,91 & $-4,88$ & $-10,51$ & 42,04 & 42,04 \\
\hline & & III & 21,07 & 26,89 & 68,51 & $-3,99$ & 112,48 \\
\hline \multirow[t]{3}{*}{ BW } & 1 & I & 24,11 & 22,06 & 69,78 & $-1,15$ & 114,80 \\
\hline & & II & $-2,71$ & $-2,30$ & $-2,52$ & 82,36 & 74,83 \\
\hline & & III & 24,11 & 22,06 & 69,78 & $-1,15$ & 114,80 \\
\hline \multirow[t]{3}{*}{ BW } & DP & I & 17,68 & 21,29 & 69,43 & $-1,69$ & 106,71 \\
\hline & & II & $-0,91$ & $-4,88$ & $-10,71$ & 42,00 & 27,56 \\
\hline & & III & 17,68 & 21,29 & 69,01 & $-1,69$ & 106,71 \\
\hline \multirow[t]{3}{*}{ PB } & DP & I & 52,51 & 36,96 & 55,03 & $-29,46$ & 115,04 \\
\hline & & II & $-4,03$ & 7,12 & 2,42 & 76,96 & 82,47 \\
\hline & & III & 35,67 & 42,58 & 31,27 & 20,54 & 130,06 \\
\hline \multirow[t]{3}{*}{ ELS } & -6. & I & 69,30 & 45,75 & 37,29 & $-12,05$ & 140,29 \\
\hline & & II & $-2,71$ & $-2,30$ & $-2,52$ & 82,36 & 74,83 \\
\hline & & III & 44,32 & 23,49 & 16,16 & 62,99 & 146,96 \\
\hline \multirow[t]{3}{*}{ MUL } & - & I & 66,85 & 45,09 & 43,87 & $-10,75$ & 145,06 \\
\hline & & II & $-2,71$ & $-2,30$ & $-2,52$ & 82,36 & 74,83 \\
\hline & & III & 44,58 & 34,38 & 40,08 & 52,90 & 171,94 \\
\hline
\end{tabular}

$\mathrm{PER}=$ percentual de tubérculos comerciais (percentage of marketable tubers); $\mathrm{MME}=$ massa média de tubérculos (average tuber weight); MTT = massa total de tubérculos (total tuber yield); TEX = textura de película (tuber skin texture); ${ }^{1}$ Massa total de tubérculos como caráter principal (total tuber weight as principal trait); ${ }^{2}$ Textura como caráter principal (texture as principal trait); ${ }^{3}$ Todos caracteres como principais (all traits considered as principal); ${ }^{4}$ Coeficiente de variação genético (coefficient of genetic variation); ${ }^{5}$ Desvio-padrão genético (genetic standard deviation); ${ }^{6}$ Método que utiliza valores mínimos para seleção (method that uses minimum values for selection).

por Neder et al. (2010) e por Silva et al. (2009). A relação CVg/CVe assumiu valores superiores à unidade para todos os caracteres, que são considerados ideais para seleção (Cruz \& Carneiro, 2006) e semelhantes aos relatados por Silva et al. (2012).
A estimativa de herdabilidade caracteriza a eficiência do valor genotípico como preditor do valor fenotípico (Cruz, 2005). Os coeficientes de herda- 
bilidade estimados no presente estudo concordam com os valores relatados por Benites \& Pinto (2011) em estudo de ganho genético em três ciclos de seleção recorrente. Mas as estimativas de herdabilidade para massa total de tubérculos e percentual de tubérculos comerciais foram inferiores às relatadas por Bearzoti et al. (1997), e para massa média dos tubérculos, o valor encontrado foi superior. Em relação ao caráter textura de película, a estimativa de herdabilidade obtida neste estudo foi similar às estimativas encontradas por Love et al. (1997), e mais elevada que os valores relatados por Silva et al. (2008), em estudo com três populações híbridas de batata derivadas de genitores com diferentes texturas de película.

Os ganhos diretos estimados por seleção foram superiores aos ganhos indiretos para os caracteres textura, percentual de tubérculos comerciais e massa total de tubérculo (Tabela 1). $\mathrm{O}$ caráter massa média dos tubérculos teve ganho direto menor que o ganho indireto em relação ao percentual de tubérculos comerciais, o que, segundo Falconer (1987), é explicado pelo fato de a seleção indireta ser superior à seleção direta se o caráter secundário apresenta maior herdabilidade do que o caráter principal ou, se a intensidade de seleção no caráter secundário for bem maior do que no principal, ou ainda, se a correlação genética entre os dois caracteres for alta, o que é o caso.

Todos os caracteres apresentaram elevados ganhos com a seleção direta, com destaque para percentual de tubérculos comerciais e massa total de tubérculo (Tabela 1). Quanto ao ganho total pela seleção direta, os caracteres massa média dos tubérculos, percentual de tubérculos comerciais e massa total de tubérculo proporcionaram os valores mais elevados quando considerados como principais.

Os ganhos obtidos pelo índice clássico de Smith (1936) e Hazel (1943) (SH) no caráter principal foram semelhantes aos ganhos por seleção direta, com uma pequena superioridade do último método (Tabela 1). O maior ganho individual foi estimado para os caracteres percentual de tubérculos comerciais e massa total de tubérculo, que foi semelhante ao encontrado pela seleção indireta, entretanto, os caracteres massa média dos tubérculos e textura da película também apresentaram valores altos. O caráter massa média dos tubérculos apresentou ganho individual menor que $\mathrm{o}$ indireto de percentual de tubérculos comerciais, que foi semelhante ao da seleção indireta.

Quanto aos ganhos totais pelo índice $\mathrm{SH}$, este demonstrou superioridade à seleção indireta para todos os caracteres, uma vez que os ganhos indiretos para maioria dos caracteres são mais elevados neste índice. A superioridade deste método já foi relatada anteriormente por Costa et al. (2004).

Comparando os genótipos selecionados pelos dois métodos, obtiveram-se coincidências acima de $80 \%$ para todos os caracteres, sendo $80 \%$ para percentual de tubérculos comerciais, $80 \%$ para massa total de tubérculo, $90 \%$ para textura da película e $80 \%$ para massa média dos tubérculos, demonstrando coincidência entre os genótipos superiores selecionados pelos dois métodos.

Embora tenha proporcionado a maximização dos ganhos individuais, a seleção direta não possibilitou a obtenção de níveis satisfatórios para os demais caracteres. Ao utilizar índices de seleção, foi possível obter uma distribuição de percentual de ganhos mais homogênea para os caracteres sob seleção, quando considerados todos os caracteres como principal (Tabela 2). Nota-se também a semelhança entre as estimativas de ganhos totais e para cada caráter, pelo emprego dos índices $\mathrm{SH}$, índice base (BW) e índice baseado na soma de ranks (MM) ao utilizar como peso econômico o DP, quando considerados percentual de tubérculos comerciais, massa média e massa total de tubérculo como principais (Tabela 2 ), em relação às estimativas obtidas pela seleção direta para massa total de tubérculo (Tabela 1), verificando que a utilização destes índices nestas situações não trazem benefícios adicionais, resultado semelhante já citado anteriormente (Barbosa \& Pinto, 1998).

Quanto aos ganhos totais, destacaram-se os índices $\mathrm{SH}, \mathrm{MM}, \mathrm{BW}$, índice baseado nos ganhos desejados (PB), índice livre de pesos e parâmetros (ELS) e índice multiplicativo (MUL), cujos maiores ganhos foram encontrados quando utilizando todos os caracteres como principais, exceto para o índice $\mathrm{SH}$, utilizando $\mathrm{CVg}$, que os ganhos totais foram superiores quando os caracteres percentual de tubérculos comerciais, massa média e massa total de tubérculo foram utilizados como principais (Tabela 2). Ao comparar os índices $\mathrm{SH}, \mathrm{MM}, \mathrm{BW}$ e PB, adotando como peso econômico o DP, o índice PB apresentou ganhos totais superiores ao considerar todos caracteres como principais.

As estimativas de ganhos totais evidenciaram superioridade nos índices MUL e MM quando todos os caracteres foram considerados como principais. Para o índice MM o maior ganho total foi quando se adotou o CVg como peso econômico. Resultados semelhantes foram reportados por Barbosa \& Pinto (1998), que sugeriram o índice MM, por ser promissor em programas de melhoramento de batata, apresentando ganhos percentuais bem distribuídos para cada caráter. Este índice também tem sido sugerido por outros autores (Costa et al., 2004; Vasconcelos et al., 2010). Outros índices que também se destacaram com elevados ganhos totais foram ELS e MM, quando utilizados os caracteres percentual de tubérculos comerciais, massa média e massa total de tubérculo como principais.

Analisando cada situação de consideração dos caracteres principais, constata-se superioridade do índice MUL, quando todos os caracteres são considerados como principais, bem como na situação em que percentual de tubérculos comerciais, massa média e massa total de tubérculo foram considerados como principais. Quando o caráter textura foi considerado como principal, a superioridade foi constatada com o índice $\mathrm{MM}$ ao empregar o $\mathrm{CVg}$ como peso econômico, entretanto, os ganhos totais quando este caráter foi adotado como principal são acentuadamente inferiores que nas outras duas situações.

Os resultados encontrados neste estudo concordam com Barbosa \& Pinto (1998), os quais alcançaram eficiência no uso dos índices na seleção de clones de batata. Em soja, Costa (2004) tam- 
bém obteve ganhos totais superiores com a utilização dos índices de seleção, por apresentarem boa distribuição de ganhos em todos os caracteres, com destaque para o índice MM, semelhante ao encontrado neste estudo. Ainda, os resultados deste trabalho estão de acordo com Pedrozo et al. (2009), em estudo com cana-de-açúcar, no qual o índice MUL foi o que revelou maior eficiência na seleção de genótipos superiores.

Os resultados encontrados neste estudo permitem concluir que o uso de índices de seleção em batata resulta em maiores ganhos totais, com uma distribuição mais equilibrada entre todos os caracteres avaliados. Os melhores índices de seleção para serem utilizados em programas de melhoramento de batata são o índice multiplicativo de Subandi et al. (1973) e o índice de ranks de Mulamba \& Mock (1978).

\section{AGRADECIMENTOS}

Os autores agradecem ao CNPq e a Capes pelo apoio e concessão de bolsas de estudo. Emerson Lenz é bolsista de PIBIC/CNPq da Embrapa Clima Temperado.

\section{REFERÊNCIAS}

BARBOSA MHP; PINTO CABP. 1998. Eficiência de índices de seleção na identificação de clones superiores de batata. Pesquisa Agropecuária Brasileira 33: 149-156.

BEARZOTI E; PINTO CABP; OLIVEIRA MS. 1997. Comparação entre métodos estatísticos na avaliação de clones em um programa de melhoramento de batata. Pesquisa Agropecuária Brasileira 32: 877-884.

BENITES FRG; PINTO CABP. 2011. Genetic gains for heat tolerance in potato in three cycles of recurrent selection. Crop Breeding and Applied Biotechnology 11: 133-140.
COSTA MM; MAURO AO; TREVISOLI SHU; ARRIEK NHC; BÁRBARO IM; MUNIZ FRS. 2004. Ganho genético por diferentes critérios de seleção em soja. Pesquisa Agropecuária Brasileira 39: 1095-1102.

CRUZ CD. 2005. Princípios da genética quantitativa. Viçosa: Editora UFV, 394p.

CRUZ CD. 2006. Programa Genes: Biometria. Viçosa: Editora UFV, 382p.

CRUZ CD; CARNEIRO PCS. 2006. Modelos biométricos aplicados ao melhoramento genético. Viçosa: Editora UFV, 585p.

ELSTON RC. 1963. A weight free index for the purpose of ranking of selection with respect to several traits at a time. Biometrics 19: 85-87.

FALCONER DS. 1987. Introduction to quantitative genetics. 2. ed. London: Longman. 340p.

FAOSTAT. 2012. The agricultural production domain covers. Disponível em: $<$ http://www. fao.org/crop/statistics.html>. Acessado em 17 jul. 2012.

FEDERER WT. 1955. Experimental designtheory and application. New York, 544p.

GRANATE MJ; CRUZ CD; PACHECO CAP. 2002. Predição de ganho genético com diferentes índices de seleção no milho pipoca CMS-43. Pesquisa Agropecuária Brasileira 37: 1001-1008.

HAZEL LN. 1943. The genetic basis for constructing selection indexes. Genetics 28 : 476-490.

LAMBERT ES; Pinto CABP; MENEZES CB. 2006. Potato improvement for tropical Biotechnology 6: 185-193.

LOVE SL; WERBNER BK; PAVEK JJ. 1997. Selection for individual traits in the early generations of a potato breeding program dedicated to producing cultivars with tubers having long shape and russet skin. American Potato Journal 74: 199-213.

MARTINS IS; CRUZ CD; REGAZZI AJ; PIRES IE. 2003. Eficiência da seleção univariada direta e indireta e de índices de seleção em Eucalyptus grandis. Revista Arvore 27: 327-333.

MULAMBA NN; MOCK JJ. 1978. Improvement of yield potential of the Eto Blanco maize (Zea mays) population by breeding for plant traits. Egyptian Journal of Genetics and Cytology 7: 40-57.

NEDER DG; PINTO CABP; MELO DS; LEPRE AL; PEIXOUTO LS. 2010. Seleção de clones de batata com resistência múltipla à pinta preta e aos vírus X e Y. Ciência Rural 40: 1702-1708
PEDROZO CA; BENITES FRG; BARBOSA MHP; RESENDE MDV; SILVA FL. 2009. Eficiência de índices de seleção utilizando a metodologia REML/BLUP no melhoramento de cana-de-açúcar. Scientia Agraria 10 : 31-36.

PEREIRA AS. 2003. Desenvolvimento de cultivares nacionais de batata. Batata Show 7: 12-13.

PESEK J; BAKER RJ. 1969. Desired improvement in relation to selected indices. Canadian Journal of Plant Science 49: 803-804.

PINELLI LLO; MORETTI CL; ALMEIDA GC; ONUKI ACA; NASCIMENTO ABG. 2005. Caracterização química e física de batatas 'Ágata' minimamente processadas, embaladas sob diferentes atmosferas modificadas ativas. Pesquisa Agropecuária Brasileira 40: 10351031.

ROSS H. 1986. Potato breeding: problems and perspectives. Advances in Plant Breeding. Supplement, Hamburg: Paul Parey. 196p.

SILVA GO; CASTRO CM; TERRES LR; ROHR A; SUINAGA FA; PEREIRA AS. 2012. Desempenho agronômico de clones elite de batata. Horticultura Brasileira 30: 557-560.

SILVA GO; PEREIRA AS; SOUZA VQ; CARVALHO FIF; NETO RF. 2007. Parâmetros genéticos em primeiras gerações de seleção de batata (Solanum tuberosum). Magistra 19: 98-103.

SILVA GO; PEREIRA AS; SOUZA VQ; CARVALHO FIF; VIEIRA EA. 2008. Qualidade de película de famílias clonais de batata. Bragantia 67: 633-638.

SILVA GO, VIEIRA JV; VILELA MS. 2009. Seleção de caracteres de cenoura cultivada em dois sistemas de produção agroecológicos no Distrito Federal. Revista Ceres 56: 595-601.

SMITH HF. 1936. A discriminant function for plant selection. Annual Eugenics 7: 240-250.

SUBANDI W; COMPTON A; EMPIG LT. 1973. Comparison of the efficiencies of selection indices for three traits in two variety crosses of corn. Crop Science 13: 184-186.

TAI GCC. 1977. Index selection with desired gains. Crop Science 17: 182-183.

TAI GCC; YOUNG DA. 1984. Early generation selection for important agronomic characteristics in potato breeding populations. American Potato Journal 61: 419-434.

VASCONCELOS ES; FERREIRA RP; CRUZ CD; MOREIRA A; RASSINI JB; FREITAS AR. 2010. Estimativas de ganho genético por diferentes critérios de seleção em genótipos de alfafa. Revista Ceres 57: 205-210.

WILLIANS JS. 1962. The evaluation of a selection index. Biometrics 18: 375-393. 